\title{
Problemas de governança em cooperativas de produtores de leite no Estado do RS
}

\author{
Governance problems in dairy farmers' cooperatives in the state of RS
}

\begin{abstract}
Resumo
As cooperativas agrícolas são estruturas econômicas intermediárias que apresentam direitos de propriedade difusos acarretando problemas de governança e ineficiência econômica. Este estudo propôs-se a analisar a existência dos problemas do horizonte e do carona em cooperativas de produtores de leite familiares do Rio Grande do Sul. Para tal, utilizou-se uma amostra intencional não probabilística onde foram pesquisadas duas cooperativas. Foram aplicados 31 roteiros de entrevistas semiestruturadas aos cooperados, funcionários e presidentes das organizações. Os resultados revelaram que os cooperados possuem visão de curto prazo (restrita à sua propriedade agrícola). Quanto à visão dos cooperados sobre o seu papel nas organizações este é pouco claro gerando espaço para ações oportunistas nas mesmas. Conclui-se que os problemas oriundos dos direitos de propriedade difusos se manifestaram nas organizações analisadas e geram ineficiências nas suas governanças.
\end{abstract}

Palavras-chave: governança; direitos de propriedade; cooperativas agrícolas.

\begin{abstract}
Abstract: Agricultural cooperatives are intermediate economic structures that have diffuse property rights leading to problems of governance and economic inefficiency. This study aimed to analyze the existence of the problems of the horizon and the ride in cooperatives of family dairy farmers in Rio Grande do Sul. For this purpose, a non-probabilistic intentional sample was used in which two cooperatives were researched. Thirtyone semi-structured interview scripts were applied to the cooperative, employees and presidents of the organizations. The results revealed that the cooperative members have short-term view (restricted to his farm). As for the view of the cooperative about their role in organizations, it is unclear, generating space for opportunistic actions in them. We conclude that the problems stemming from diffuse property rights have manifested themselves in the analyzed organizations and generate inefficiencies in their governance.
\end{abstract}

Keywords: governance; property rights; agricultural cooperatives.

Renata Milani ${ }^{\mathrm{I}}$, Mariele Boscardin ${ }^{\mathrm{II}}$, Marcelino de Souza ${ }^{\mathrm{III}}$, Adriano Lago $^{\mathrm{IV}}$, Rosani Marisa Spanevello ${ }^{\mathrm{V}}$

${ }^{\text {I } U n i v e r s i d a d e ~ F e d e r a l ~ d o ~ R i o ~ G r a n d e ~ d o ~ S u l ~-~ U F R G S . ~ P o r t o ~ A l e g r e, ~ R S ~ r e n a t a m i l a n i 17 @ y a h o o . c o m . b r ~}$

${ }^{\text {II }}$ Universidade Federal de Santa Maria - (UFSM). Santa Maria, RS marieleboscardin@hotmail.com

III Universidade Federal do Rio Grande do Sul - UFRGS. Porto Alegre, RS marcelino.souza@uol.com.br

IV Universidade Federal de Santa Maria - (UFSM). Santa Maria, RS adrianolago@yahoo.com.br

${ }^{\mathrm{V}}$ Universidade Federal de Santa Maria - (UFSM). Santa Maria, RS rspanevello@yahoo.com.br 


\section{Introdução}

Historicamente, as cooperativas se configuram como arranjos coletivos com atuação direta nas necessidades de seus associados. No caso do setor agropecuário, estas organizações têm propiciado, ao longo do tempo, benefícios que vão desde o fornecimento de insumos, a assistência técnica, o armazenamento, a comercialização e a industrialização da produção até o fornecimento de crédito. Em muitos casos, as cooperativas também são agentes locais ativos na busca de melhoria da qualidade de vida nas regiões onde estão inseridas, participando de discussões que envolvem saúde, educação e infraestrutura, por exemplo.

Neste sentido Benecke (1980) definiu as cooperativas de forma semelhante à Aliança Cooperativa Internacional (ACI). Entretanto, o referido autor se atém ao duplo papel que os cooperados ocupam em relação à sociedade cooperativa, o papel de donos e usuários.

Ferreira (2014), pesquisando cooperativas agropecuárias do Rio Grande do Sul, identificou uma série de benefícios que estas oferecem aos seus associados. O autor os classificou em três abordagens centrais: benefícios estruturantes, benefícios operacionais e benefícios ampliados. Os benefícios estruturantes são aqueles relacionados ao propósito central da maioria das cooperativas: garantia de compra da produção mediante uma remuneração justa. Os benefícios operacionais tratam de todas as ações de apoio ao dia a dia dos cooperados: assistência técnica, financiamentos, convênios na área de saúde e comércio. Os benefícios ampliados se referem à distribuição de sobras e o compromisso social e regional das cooperativas.

Bialoskorski Neto (1998) argumenta que a principal razão para a existência de estruturas econômicas intermediárias, como as cooperativas, centra-se no fato de que estas possibilitam uma diminuição de riscos e uma agregação de valor para os produtores rurais que, isoladamente, na maioria das vezes, não teriam condições favoráveis de relacionamento com os mercados concentrados.

No caso da agricultura familiar, Christoplos (2010) destaca que os pequenos produtores rurais estão sendo colocados para fora do mercado em função das limitações impostas pelo mercado das principais commodities, ou seja, um aperto (pricesqueeze) sobre as condições de produção dos agricultores que tem levado aos processos de descapitalização e inviabilidade econômica.

Tendo em vista importância do cooperativismo, e em especial para agricultura familiar, faz-se necessário compreender mais detalhadamente as características e peculiaridades dessas organizações. Quando se parte do pressuposto de que a cooperativa é caracterizada pela união de pessoas para o exercício de uma atividade econômica, de proveito comum, sem objetivo de lucro, identifica-se a existência de duas dimensões nessas organizações: uma econômica e outra social.

Por isso, Pinho (1982) já argumentava que as cooperativas acarretam muitas dificuldades aos seus gestores, pois combinam os caracteres de associação e de empresa. Se estes priorizarem o aspecto associativo, correrão o risco de encontrar problemas na gestão financeira. Por outro lado, se considerarem apenas o aspecto empresarial, poderão distanciar-se dos cooperados e esquecer suas finalidades sociais. Assim, o ideal seria o equilíbrio entre ambos os enfoques.

Corroborando com esta ideia, Boesche e Mafioletti (2005) destacam que manter o equilíbrio entre as dimensões social e econômica é o principal desafio do cooperativismo, já que o ambiente de competição das cooperativas é o mesmo de todas as outras organizações. Neste sentido, Bialoskorski Neto (2001) ressalta que o desempenho econômico e de mercado é condição fundamental para o bom desempenho social das cooperativas.

Bitencourt, Amodeo e Valadares (2010) destacam que a dupla natureza do cooperado como dono e usuário exigirá alienar os objetivos da empresa aos do associado. Esse duplo papel do cooperado é característico desse tipo de organização, uma vez que a cooperativa se constitui em uma associação, enquanto reunião de pessoas, e em um empreendimento, enquanto junção de capitais.

Reforçando esta ideia Barton (1989) aponta que o direito de controle do cooperado não muda de acordo com a sua cota de capital, isto é, a alocação do controle é um voto por proprietário independentemente do volume de capital que o mesmo possui na organização. Cook (1995) sintetiza esta afirmação: "As cooperativas diferem das demais organizações por duas razões: os cooperados são simultaneamente proprietários, usuários e consumidores dos seus produtos e serviços e o direito ao controle não é vinculado ao direito ao resíduo". 
Os argumentos apresentados anteriormente, referentes às dimensões econômica e social das cooperativas e ao duplo papel do associado como dono e usuário do empreendimento fazem frente a uma série de aspectos que culminam com o fato de as cooperativas serem consideradas organizações complexas do ponto de vista da gestão.

Neste sentido, Cook (1995) ao analisar o ciclo de vida de cooperativas agropecuárias americanas, descreve alguns problemas que podem surgir a partir da falta de direitos de propriedade claramente definidos. Estes problemas de governança oriundos dos direitos de propriedade prolixos e difusos podem dificultar a gestão e capitalização das cooperativas uma vez que os associados não conhecem efetivamente sua propriedade na cooperativa. A melhor alocação dos direitos mitiga esses problemas, melhora o seu desempenho e, consequentemente, aumenta a probabilidade de sobrevivência das cooperativas (Costa, 2010).

Neste sentido, conforme explicita Valadares (2003), os associados assumem essa dupla condição de donos e usuários quando investem o seu capital na cooperativa e, simultaneamente, quando se utilizam dos serviços oferecidos por ela. Devido a isso, Antonialli (2000) destaca que sempre haverá conflitos de interesse no que se refere às estratégias da organização e às estratégias dos cooperados, enquanto empresários individuais.

No Brasil estudos recentes como de Serigati (2008) e Pivoto (2013) demonstram que estes problemas inicialmente encontrados e analisados em cooperativas americanas estão presentes em cooperativas brasileiras. Entretanto, as cooperativas que foram estudadas no Brasil assim como, as que estudadas por Cook (1995) são cooperativas com perfil empresarial, com um número expressivo de associados; que trabalham de maneira especializada; com percentual importante de produção agrícola/agroindustrial voltada à exportação.

Tendo em vista a relevância do trabalho realizado por Cook (1995) e a sua utilização em estudos no Brasil, bem como o perfil diferenciado das cooperativas de produtores familiares, tem-se como objetivo neste estudo analisar a existência do problema do horizonte e do carona em duas cooperativas de produtores de leite familiares do Rio Grande do Sul.

\section{Organizações cooperativas sob a ótica da nova economia institucional}

Embora a Nova Economia Institucional (NEI) seja predominantemente orientada por uma abordagem econômica, esta abordagem busca combinar contribuições de diferentes disciplinas para explicar a natureza, funcionamento e evolução de uma ampla variedade de instituições, dentre estas as instituições cooperativas. De acordo com Sykuta e Cook (2001), a NEI engloba três áreas da economia das organizações, a saber: teoria dos custos de transação; teoria da agência e teoria dos direitos de propriedade. Desta forma, estruturas de governança podem ser utilizadas para minimizar os custos de transação.

Langlois e Foss (1997) ressaltam a relevância de Ronald Coase, o qual introduziu em seu célebre artigo "The nature of the firm", em 1937, uma nova perspectiva para o entendimento das estratégias empresariais, ao mostrar que existem outros custos além dos custos de produção, custos estes que estão relacionados ao funcionamento dos mercados: os custos de transação. Estes são os gastos que os agentes econômicos enfrentam todas as vezes que recorrem ao mercado, ou seja, são aqueles custos para negociar, redigir e garantir que os contratos sejam cumpridos.

A economia dos custos de transação (ECT) é uma teoria que permite analisar as organizações e o seu relacionamento com o mercado e as instituições a partir das características das transações e de pressupostos comportamentais dos agentes envolvidos (Augusto et al, 2014). De acordo com Williamson (1985) os atributos que caracterizam uma transação são três: a frequência, a incerteza e a especificidade de ativos, sendo este último, na visão do autor, o principal determinante da estrutura de governança a ser adotada.

A partir dos trabalhos de Oliver Williamson, a ECT foi responsável em subsidiar um novo olhar para a defesa de concorrência que até então era vista somente como uma forma de subtrair um fornecedor de seus concorrentes, dificultando a competição do setor e assim aumentar indiretamente o seu poder de mercado. 
Já os conflitos de agência ou Teoria do Agente-Principal foram desenvolvidos por Jensen e Meckling (1976) e tem sua raiz no utilitarismo econômico. Essa teoria tem como premissa básica a existência de um mercado regido por contratos firmados entre os agentes econômicos, quer sejam empresas, governo ou pessoas físicas (LIMA, et al 2008).

A teoria da agência tornou-se importante a partir da evolução dos mercados de capital (Lima, et al. 2008). Para Segatto-Mendes (2001) a teoria da agência proporcionou uma análise das diferentes relações contratuais existentes no seio da empresa, incluindo o conceito de relação de agência, que normalmente envolve um agente principal (proprietário) que solicita a um "agente" (gestor) que atue por sua conta e em prol de seus interesses, sendo oferecida uma remuneração em troca dos serviços. A teoria da agência relata de forma mais abrangente a possibilidade de divergência de interesses de acionistas e gestores, onde um dos agentes econômicos tenta tirar proveito de vantagens advindas de uma posição privilegiada.

$\mathrm{Na}$ seção a seguir se dará enfoque aos direitos de propriedade. Além do que, serão apresentados os problemas de governança, uma vez que, estes estão ligados os direitos de propriedade presentes nas cooperativas agroindustriais.

\section{Direitos de propriedade e os problemas de governança}

De acordo com Feijó (2010), os direitos de propriedade configuram uma instituição, uma regra social de comportamento, algo que é capaz de afetar a conduta econômica dos agentes. É a partir da Nova Economia Institucional que pesquisadores procuram estudar como os conjuntos alternativos de regras sociais e de organizações econômicas podem afetar o comportamento dos agentes, bem como a alocação de fatores e de recursos e o resultado do equilíbrio do processo focando no efeito da instituição dos direitos de propriedade sobre o resultado econômico.

Ainda de acordo com Feijó (2010), o autor Steve é um dos grandes responsáveis em resgatar a ideia de que um sistema de direitos de propriedade constitui um método para assinalar a pessoas específicas a autoridade para selecionar bens particulares para qualquer uso dentro de uma classe não proibida de usos. Para este autor esta concepção já estava presente em autores como, Armen Alchian, Guido Calabresi e Harold Demsetz os quais foram os responsáveis pelo renascimento do enfoque econômico dos direitos de propriedade.

Para os Alchianos os direitos de propriedade sob o ponto de vista econômico não estão baseados apenas na dimensão legal, mas também nas questões das normas sociais como, a etiqueta, os costumes sociais e o desejo de integração, pois, também, condicionam o uso de recursos e, portanto, circunscrevem os direitos de propriedade.

De acordo com Feijó (2010), os direitos de propriedade implicam três modalidades de direito: Direitos de utilizar um ativo da maneira que se julgar conveniente; Direito de usufruir uma renda gerada pelo ativo e de estabelecer contratos lucrativos com outros indivíduos tendo o ativo em questão como base do contrato; Direito de transferência da propriedade do ativo em caráter permanente de um indivíduo a outro mediante contrato voluntário.

Segundo Eggertsson (1990) direitos de propriedade é aquele direito de usar, de transformar ou de transferir determinado bem ou ativo. Para Hart (1995), na presença de contratos incompletos, a propriedade é uma fonte de poder, isto porque contratos incompletos podem indicar problemas de assimetria, ambiguidades ou situações não claras no uso de ativos.

Grossman e Hart (1986) definem os direitos de propriedade em uma empresa pela existência de direitos em resultados residuais, isto é, resultados ou retornos que sobram como resíduo após o pagamento de todos os fatores de produção. Nesta situação, a propriedade se expressa pela possibilidade de se apropriar destes resíduos, mas há problemas se estes não ocorrem.

Segundo Milgron e Roberts (1992), os direitos de propriedade estão divididos em dois tipos distintos e complementares: direito ao resíduo e direito ao controle. O primeiro refere-se à prerrogativa do proprietário receber os ganhos e perdas geradas, denominados de ganhos ou lucros residuais. Já o segundo dá ao proprietário autoridade, sujeita à regulação externa, para definir como os membros da organização deverão alocar os ativos a serem utilizados no sistema produtivo e os mecanismos de monitoramento, premiação ou punição dos agentes contratados para gerirem a empresa. 
Partindo de uma definição sobre os direitos de propriedade, pode-se passar para a discussão de outros autores sobre os problemas enfrentados na governança cooperativa. Uma vez que a estrutura de direitos de propriedade está associada à eficiência da firma é importante definir as suas características e implicações. No caso das cooperativas existe de acordo com Cook (1995) problemas de gestão e governança advindos de uma estrutura de propriedade vagamente definida.

Neste sentido, Bialoskorski Neto (2004) afirma que a organização cooperativa tem como lógica econômica a não definição de direitos de propriedade individuais, de forma a manter o escopo socialista da organização, além da ausência de lucro. Por outro lado, Bialoskorski Neto (1998) afirmou que estas características podem causar problemas de incentivos à participação.

É importante ressaltar que as cooperativas se distinguem das empresas. Neste sentido, para as sociedades de capital não interessa muito as pessoas que vão integrá-la. Nas sociedades de pessoas, o relacionamento entre a sociedade e seus sócios é de extrema importância: as capacidades administrativas e operacionais, além do interesse de participar dos sócios, são levadas em consideração (COSTA, JÚNIOR e SILVA, 2015).

Segundo Costa (2010), organizações de propriedade difusa e complexas devem promover a separação entre proprietários e gestores, pois essa desvinculação gera benefícios para a empresa. Assim, nas cooperativas cujo cooperado é desvinculado da gestão, o problema de controle seria mitigado e a probabilidade de sobreviver, maior.

De acordo com Cook (1995), as cooperativas possuem uma arquitetura contratual que apresenta direitos de propriedade vagamente definidos. A seguir descrevem-se estes problemas inicialmente analisados por Cook (1995) e posteriormente discutidos por autores como Bialoskorski Neto (2004) e Pivoto (2013).

O problema do carona ou freerider ocorre quando os benefícios da cooperativa acabam por beneficiar também membros não cooperativados que não têm atividades e custos para com a organização, mas que se beneficiam dos resultados econômicos desta organização. Denominado por Cook (1995) como parasitismo isso ocorre quando os novos membros obtêm o mesmo patrocínio e direitos residuais como os membros existentes. De acordo com Bialoskorski Neto (2004), esse problema é importante uma vez que, se percebido por outros agentes, não produz incentivos à participação na cooperativa.

O problema do horizonte ocorre quando um grupo de membros reivindica o lucro residual sobre o lucro líquido, entretanto este lucro é gerado por um ativo menor do que a vida produtiva deste ativo. O problema do horizonte cria um ambiente de investimento em que existe um desincentivo para os membros contribuírem para o crescimento da cooperativa. Em outras palavras, este problema indica que os cooperados possuem uma aversão em aceitar estratégias que impliquem em imobilizar capital por um longo período de tempo.

De acordo com Zylbersztajn (2002), este problema decorre do fato de que a sua riqueza não varia com o valor da empresa cooperativa, pois não há mercado para as quotas de participação. Assim, projetos de investimentos de longa duração, diferenciação de produtos e desenvolvimento de marcas serão rejeitados em detrimento de projetos de curto prazo.

Zylbersztajn (2002) afirma que ao mesmo tempo em que os princípios cooperativistas representam o elo entre as organizações no mundo cooperativista, esses mesmos princípios delimitam as estratégias passíveis a serem adotadas pelas organizações cooperativas.

Corroborando com esta ideia, Benecke (1980) afirma que a dinâmica de os donos, quando integralizam seu capital, e usuários, quando utilizam os serviços oferecidos pela cooperativa, foi denominada por critério de identidade. Isso ocorre porque em uma empresa convencional, o interesse do sócio é indireto, ele não necessariamente utiliza os serviços oferecidos pela empresa; seu interesse é restrito ao lucro que a atividade irá lhe fornecer.

O contrário ocorre nas cooperativas, pois o capital integralizado pelos cooperados cria a expectativa que a cooperativa presta- lhes alguns serviços. Espera-se que a cooperativa lhes ofereça algum tipo de serviço de apoio a suas atividades que, individualmente, teriam dificuldades de realizar. Esse critério de identidade significa também que os cooperados têm poder de manifestar seus interesses na realização de um determinado serviço e decidir sobre os rumos da cooperativa. 


\section{Estratégias usadas para minimizar os problemas de governança em cooperativas agropecuárias}

Estratégias e formas de minimizar os problemas de governança em cooperativas agropecuárias foram apontadas por alguns autores como Lazzarini, Bialoskorski Neto e Chaddad (1999), Zylbersztajn (2002), Bialoskorski Neto (2002) e Chaddad (2007).

Dentre as estratégias, destaca-se a fidelização dos cooperados. Cabe destacar que, cada vez mais as organizações cooperativas se veem confrontadas com a não fidelização dos cooperados. Isto porque no passado o associado possuía mais comprometimento com a organização. De acordo com Chaddad (2007), no passado, os associados eram mais participativos na cooperativa por razões como, por exemplo, não ter outra opção ou por razões ideológicas ou por ser a cooperativa uma organização democrática e sem fins lucrativos. Entretanto, atualmente os produtores encontram-se em situação econômica difícil, sob constante pressão para controlar (reduzir) custos e serem competitivos no mercado.

Zylbersztajn (2002) reforça que o sucesso da cooperativa depende, fortemente, do cumprimento das promessas realizadas pelos cooperados, quando tomaram a decisão colegiada de realizar o investimento. A partir desta realidade é fato que o problema do carona ou freerider descrito por Cook (1995) fica mais evidente. Ou seja, aumenta o número de associados que têm acesso aos benefícios e serviços gerados pela cooperativa, mas que não auxiliam na capitalização e crescimento da organização. Visando diminuir este problema as cooperativas buscam estratégias de fidelização dos cooperados. Conforme mencionado anteriormente o problema de descapitalização dos associados contribui para que estes busquem empresas capazes de pagar um valor superior para sua produção.

Desta forma, as cooperativas necessitam ser competitivas para conseguirem pagar um preço mais justo pelo produto. Neste sentido, Chaddad (2007) aponta que muitas cooperativas de leite distribuem os resultados aos cooperados sob a forma de prêmios ao preço do leite. Ou seja, o produtor recebe um preço competitivo pelo leite, mas também participa dos resultados da empresa cooperativa. Aportando esta questão Zylbersztajn (2002) afirma que para alguns autores os cooperados não recebem incentivos via valor da empresa, ou seja, mesmo sendo dono da cooperativa, ele prefere vender o seu produto para outra empresa se esta puder pagar um valor superior. Tal situação aponta para a existência do problema do horizonte, mostrando que o cooperado tende a tomar decisões que no curto prazo gerem benefícios para ele.

Chaddad (2007) afirma que outro mecanismo relevante usado pelas cooperativas é a comunicação. Para tal, contam com uma estrutura especializada no relacionamento com os associados. Trata - se de um centro de custos que se responsabiliza diretamente por esforços de comunicação e fidelização dos associados. Tais esforços de comunicação aumentam a fidelidade do associado, pois esse tem a percepção que tem voz e pode exercer influência sobre as decisões da cooperativa. Zylbersztajn (2002) aponta esta e outras estratégias que visam aumentar a fidelização do cooperado.

A participação do cooperado na rede coordenada pela cooperativa, a sua reputação junto da comunidade, os mecanismos de pagamento pelo produto adotado pela cooperativa, e a utilização de tecnologia de informação pela cooperativa para monitorar o cooperado são diferentes dimensões que devem ser consideradas ao lidar com o problema. Chaddad (2007) aponta também que algumas cooperativas adotam contratos de comercialização. A respeito disso Zylbersztajn (2002) explana que os membros das cooperativas podem fazer contratos formais com a cooperativa, assim como ocorre a realização de contratos com outras organizações. A quebra contratual ex-postleva à perda de valor dos ativos investidos, dificultando o planejamento de longo prazo e a estabilidade das relações entre as partes.

A próxima seção deste artigo apresenta os procedimentos metodológicos utilizados na pesquisa que deu origem a este artigo. 


\section{Aspectos metodológicos da pesquisa}

A maior base de dados referente às cooperativas de produtores familiares é a base de dados do programa "Mais Gestão", e a utilização desta base de dados se justificou para escolha das organizações cooperativas que fizeram parte da pesquisa. Este programa foi gerido através do extinto Ministério do Desenvolvimento Agrário (MDA) e consistiu em uma metodologia de Assistência Técnica e Extensão Rural (ATER) orientada para as cooperativas da agricultura familiar, especialmente àquelas atuantes nas cadeias de gêneros alimentícios e do biodiesel.

Por meio deste banco de dados constatou-se no Estado do Rio Grande do Sul a existência de 92 cooperativas atendidas na primeira etapa do programa iniciado em 2012. Das 92 cooperativas assistidas pelo programa observou-se que seis cooperativas são constituídas por produtores de leite, sendo esta a principal atividade econômica destas organizações.

Partindo das informações, realizou-se um contato prévio com as seis cooperativas no intuito de iniciar um estudo exploratório que teve como objetivo nos auxiliar na delimitação dos problemas de governança que os presidentes das cooperativas consideravam mais importantes nestas organizações. E, a partir disso, delimitar os problemas que seriam abordados com mais profundidade neste estudo.

Assim, realizou-se contatos com estas organizações no início do mês de maio de 2016. Após estes contatos prévios realizados por telefone enviou-se para estas cooperativas um questionário estruturado abordando os cinco problemas de governança descritos por Cook (1995). A partir das respostas dos entrevistados das cooperativas ao questionário procedeu-se a seleção das cooperativas. As cooperativas selecionadas estão localizadas nos municípios de Ibiaçá e Crissiumal, ambas no Estado do Rio Grande do Sul.

A escolha das cooperativas deu-se, por conveniência. Esta técnica é muito comum e consiste em selecionar uma amostra da população que seja acessível. Geralmente, essa conveniência representa uma maior facilidade operacional e baixo custo de amostragem. Além disso, as regiões e cooperativas selecionadas apresentam particularidades que justificaram a seleção das mesmas. As cooperativas estão localizadas em uma região que se destaca nacionalmente pela produção leiteira, e que eram integrantes de um programa voltado para o fortalecimento das cooperativas de agricultores familiares através do aprimoramento dos processos de gestão destas organizações.

A técnica de pesquisa utilizada para coleta de dados foi a entrevista semiestruturada com questões abertas. O roteiro foi construído de maneira a contemplar questões para caracterizar as cooperativas e o perfil dos respondentes, além de questões que permitissem verificar a trajetória, os problemas do carona e do horizonte presentes nas cooperativas, bem como, identificar a existência de estratégias para minimizar estes problemas.

Foram entrevistados em Ibiaçá 10 produtores, além do presidente e 6 funcionários. Já na cooperativa de Crissiumal foram entrevistados 11 produtores de leite além do presidente e dos dois funcionários da cooperativa totalizando assim 31 entrevistas nas duas cooperativas. As entrevistas foram realizadas no segundo semestre de 2016.

Após a coleta dos dados estes foram sistematizados e analisados com auxílio do software para análise qualitativa, webQDA. Inicialmente procedeu-se a organização dos dados coletados, desta forma, as entrevistas gravadas foram transcritas para o Word e posteriormente transferidas para o software webQDA. Em seguida foram criadas categorias para organizar as respostas obtidas nas entrevistas, já que, sendo um roteiro aberto, as respostas podem variar bastante.

\section{Análise dos resultados}

\subsection{Breve caracterização das organizações cooperativas analisadas}

Inicia-se a apresentação e discussão dos resultados trazendo algumas características das organizações cooperativas analisadas. Tem-se por objetivo apresentar um sintético perfil das cooperativas que podem estar relacionadas com os problemas de governança analisados. 
No que se refere ao tempo de formação das cooperativas analisadas, tem-se que, a cooperativa de Ibiaçá foi fundada em 1994, portanto, está completando 21 anos. No momento de sua formação esta cooperativa possuía 213 associados. A cooperativa de Crissiumal teve sua formação mais recente, em 2008, sendo que no momento de sua formação possuía em seu quadro 880 associados.

Atualmente em ambas as cooperativas o que se percebe é que a grande maioria dos associados não realiza a comercialização do leite. Isto ocorre por dois motivos distintos. O primeiro está no fato de que muitos produtores de leite deixaram a atividade e o segundo é que alguns associados passaram a comercializar o leite com outras cooperativas ou empresas. Em se tratando das demais operações como as compras no mercado e loja agropecuária, existe clara diferença entre as duas cooperativas. Na cooperativa de Ibiaçá todos os entrevistados afirmaram que realizam estas operações apenas com a cooperativa. Já na cooperativa de Crissiumal apenas 27,3\% dos entrevistados afirmaram realizar estas operações exclusivamente com a cooperativa.

Estes dados podem ser preocupantes, uma vez que, de acordo com Maraschin (2004) é o relacionamento comercial a base da sustentação dos negócios de uma cooperativa, é o cooperado, ao transacionar com a cooperativa, quem sustenta o empreendimento. Portanto, a baixa fidelidade dos cooperados pode ser responsável pelo insucesso desta organização.

Em se tratando dos objetivos e motivações que levaram a formação das cooperativas tem-se que as respostas dos presidentes das organizações não diferem muito. Segundo eles o principal objetivo ao formar as cooperativas era a busca por um preço superior pelo litro do leite, ou seja, aumentar o poder de barganha dos produtores rurais. Isto corrobora com as afirmações de Cook (1995) sobre os objetivos que levam à formação de uma cooperativa.

Neste sentido, verificou-se que a cooperativa de Ibiaçá contava com 73 associados que comercializavam o leite com a cooperativa. Já a cooperativa de Crissiumal contava com 80 associados comercializando o leite com a mesma. No que tange ao volume de leite comercializado mensalmente pelas organizações cooperativas, tem-se que, a média de leite comercializado pela cooperativa de Ibiaçá é superior ao da cooperativa de Crissiumal possuindo um número menor de associados. Isso ocorre devido ao fato da média de produção por associado ser superior na cooperativa de Ibiaçá, possuindo uma média mensal de 5.200 litros, enquanto que, na cooperativa Crissiumal a média de produção por associado perfaz a média de 1.718 litros mensais. Esta característica da cooperativa Crissiumal em comprar o leite de produtores com baixa produção diária é uma estratégia utilizada nos últimos anos.

Além da atividade principal destas cooperativas, estas apresentam outras atividades que estão relacionadas com a atividade leiteira. Ambas as cooperativas possuem uma loja agropecuária em que são comercializados os principais produtos que envolvem a produção leiteira. Já a cooperativa de Ibiaçá conta ainda com um mercado. No início da sua formação a cooperativa de Crissiumal também apostou na diversificação de suas atividades através de um mercado e ainda ampliou suas atividades por meio de uma agroindústria de beneficiamento de mandioca, entretanto, ambas as atividades tiveram insucesso após curto período de duração.

\subsection{Análise dos problemas do carona e horizonte sob a ótica dos cooperados}

Inicialmente traz-se à discussão os resultados que competem ao problema do horizonte. Conforme observa-se na Tabela 1, ao questionar-se os cooperados sobre o que eles consideram mais interessante em relação ao preço, ou retorno em sobras operacionais, tem-se que a maioria das respostas demonstram que é mais relevante receber um preço superior pelo leite mensalmente.

Destaca-se o depoimento do cooperado da cooperativa de Ibiaçá o qual enfatiza que a importância do preço superior sendo uma forma de manter os cooperados mais fiéis à cooperativa: "eu acho que o preço por litro é mais importante porque ajuda manter na cooperativa, produtores que produzem mais. Se a cooperativa pode competir com o preço das empresas então é mais fácil manter quem tem maior produção". 
Tabela 1: Preferência dos cooperados em relação ao preço do produto ou sobras operacionais.

\begin{tabular}{c|c|c|c|c|c|c}
\hline $\begin{array}{c}\text { Cooperativ } \\
\text { a }\end{array}$ & $\begin{array}{c}\text { Preço superior } \\
\text { mensalmente }\end{array}$ & $\begin{array}{c}\text { Sobras } \\
\text { operacionais }\end{array}$ & $\begin{array}{c}\text { Preço mais } \\
\text { homogêneo }\end{array}$ & $\begin{array}{c}\text { Preço } \\
\text { superior e } \\
\text { sobras }\end{array}$ & $\begin{array}{c}\text { Facilidade } \\
\text { para negociar } \\
\text { pagamento }\end{array}$ & Indiferente \\
\hline Ibiaçá & 5 & 3 & 2 & 2 & 1 & 0 \\
\hline Crissiumal & 7 & 3 & 1 & 0 & 1 & 1 \\
\hline
\end{tabular}

Fonte: Elaborado pelos autores com base nos dados da pesquisa de campo, 2016.

Este resultado nos remete a discussão da diferenciação de valor aos associados que entregam um volume de leite maior do que os que entregam um volume menor para a organização. $\mathrm{O}$ associado que entrega um volume maior é mais visado por outras empresas, mas, também seu volume de produção é importante para o poder de barganha da cooperativa. Desta forma, fica a questão, a cooperativa deve pagar um preço diferente para os produtores de maior e menor volume de produção? Traz-se também o depoimento da associada da cooperativa de Crissiumal representando a opinião de outros cooperados da mesma organização. "Para mim o que é melhor é que a cooperativa pague um preço bom todo mês porque os gastos que a gente tem também são mensais".

Os resultados obtidos por Maraschin (2004), ao investigar cooperativas com características empresariais corroboram os resultados obtidos nesta pesquisa, uma vez, que ao analisar uma cooperativa de grãos e leite no Rio Grande do Sul, a autora encontrou que $70 \%$ dos cooperados preferem receber preços superiores pelo produto, pois, as sobras são pouco significativas. Os resultados obtidos na pesquisa de Pivoto (2013) também apoiam estes resultados. Assim, a partir dos resultados encontrados neste estudo e também por outros autores fica evidente a visão de curto prazo dos cooperados.

Em seguida, as informações contidas na Tabela 1 revelam que alguns cooperados que destacam a importância das sobras operacionais como sendo mais relevantes. Esse resultado é confirmado através do depoimento do entrevistado da Cooperativa de Ibiaçá: "as sobras são mais importantes e devem ser mais valorizadas porque são o diferencial em comparação com as empresas". Além das opções sugeridas na questão, os respondentes consideram outras alternativas relevantes além do preço e das sobras operacionais. Assim, destaca-se que em ambas as cooperativas alguns cooperados consideraram que é mais importante que o preço pago pelo produto seja mais homogêneo entre os cooperados. Eles não consideram justo a diferença de preço entre os cooperados, mesmo que, esta diferença seja por conta de bonificações por qualidade e quantidade produzida.

Estes depoimentos demonstram que estes cooperados possuem dificuldade em aceitar a implantação de mudanças dentro das organizações, ainda que, estas mudanças sejam exigências às quais a própria organização é obrigada a cumprir. Ainda pode demonstrar que estes produtores possuem resistência em implementar tais exigências em suas propriedades e isto pode implicar em um problema para a cooperativa, pois, esta necessita adquirir o leite dos cooperados dentro de padrões mínimos de qualidade exigidos por lei. Desta forma, a cooperativa se vê em uma posição desconfortável, na qual, ela deixa de adquirir o produto por não estar em consonância com os limites aceitos e assim pode perder o cooperado que irá buscar empresas que ainda consigam burlar as normas de inspeção sanitária.

Além disso, alguns cooperados frisam que a facilidade para negociar os pagamentos é mais relevante que o preço e as sobras. Segundo estes respondentes, somente ao comercializar com a cooperativa eles conseguem prazos maiores para pagamentos e negociar as dívidas com mais facilidade, enquanto que as outras empresas são mais rigorosas com estas questões.

Em se tratando da visão de curto de prazo dos cooperados em relação ao empreendimento cooperativo, as respostas são quase unânimes. Apenas um respondente da Cooperativa de Crissiumal 
afirma que os cooperados possuem visão de longo prazo quanto à organização cooperativa. Neste sentido, Bialoskorski Neto (2002) afirma que os cooperados estão dispostos a assumir o risco em sua propriedade, mas não estão dispostos a assumir riscos na cooperativa, de maneira a exigir resultados em curto prazo e impedindo a formação de sobras. Entretanto, estes resultados diferem dos resultados encontrados por Pivoto (2013), em que, o autor encontrou uma baixa concordância para esta questão. Segundo o autor fatores como a assistência técnica e responsabilidade social podem ter sido determinantes para este resultado. No caso das duas cooperativas analisadas apenas a cooperativa de Ibiaçá presta alguma forma de assistência técnica, através de inseminação artificial dos animais.

Tabela 2: Percepção dos cooperados com relação aos investimentos de longo prazo.

\begin{tabular}{c|c|c|c}
\hline Cooperativas & $\begin{array}{c}\text { Investimentos de longo } \\
\text { prazo são arriscados }\end{array}$ & $\begin{array}{c}\text { Investimentos de } \\
\text { longo prazo são } \\
\text { importantes }\end{array}$ & $\begin{array}{c}\text { Arriscados, } \\
\text { mas, } \\
\text { relevantes }\end{array}$ \\
\hline Ibiaçá & 3 & 4 & 3 \\
Crissiumal & 7 & 3 & 1 \\
\hline
\end{tabular}

Fonte: Elaborado pelos autores com base nos dados da pesquisa de campo, 2016.

Ainda se tratando de investimentos no longo prazo, os cooperados foram questionados sobre como eles percebem estes investimentos para a organização cooperativa. Conforme pode-se observar na Tabela 2, em ambas as cooperativas a percepção que se destaca é de que os investimentos de longo prazo são arriscados. Os argumentos para esta resposta variam bastante sendo argumentado que há muita concorrência com outras empresas e de que o momento atual é de crise e muita instabilidade, portanto, deve-se ter muito cuidado com investimentos.

Destaca-se neste sentido, a Cooperativa de Crissiumal em que a maioria dos respondentes julga arriscado a realização destes investimentos. Ao contrário do que era esperado com base nas entrevistas do presidente e funcionários da organização, em que, os mesmos afirmaram que estes investimentos são aceitos e até mesmo cobrados pelos cooperados. Percebe-se, dessa forma, que existe uma assimetria entre a forma como estes agentes percebem que os cooperados visualizam os investimentos.

Entretanto, alguns cooperados possuem uma visão diferenciada de que os investimentos de longo prazo podem ser importantes para a organização. É o que afirma o entrevistado da cooperativa de Crissiumal: "penso que se a gente tivesse condições de investir em uma fábrica e ter nossos produtos isso seria bom porque vai eliminar os atravessadores e assim aumentar os lucros". Já alguns cooperados julgam estes investimentos relevantes e ao mesmo tempo arriscados. Portanto, para estes cooperados deve-se proceder uma análise qualificada da viabilidade destes investimentos para evitar futuros prejuízos.

Ao serem questionados se os cooperados visualizam a cooperativa como uma prestadora de serviços e não como uma organização que pode trazer benefícios econômicos através das sobras operacionais, a maioria dos respondentes das duas cooperativas afirmaram que afirmativamente.

Neste sentido, Zylbersztajn (2002) afirma que em cooperativas tradicionais os cooperados não possuem clareza sobre ser dono da organização cooperativa e, portanto, reclamante dos resultados. De acordo com o autor este é um dos fatores que leva aos problemas de gestão que as cooperativas Brasileiras enfrentam. Os resultados obtidos por Pivoto (2013), corroboram com tais resultados. De acordo com o autor, na maior parte das organizações os cooperados visualizam a cooperativa apenas como prestadora de serviço e assim, não cobram melhores resultados econômicos e sobras operacionais.

Quando questionados sobre o motivo porque isso ocorre fica evidente que para a maioria dos respondentes os cooperados não tem clareza do seu papel dentro da organização. Além disso, quase a totalidade dos respondentes afirma que os cooperados podem ser considerados oportunistas e individualistas, pois, utilizam a estrutura da cooperativa quando lhes convêm. 
Em se tratando da percepção dos cooperados em relação às estratégias usadas pelas organizações para que o cooperado tenha visão de longo prazo tem-se que em ambas as cooperativas analisadas as respostas obtidas pelos respondentes não se assemelham as encontradas por outros autores. Assim, tem-se que na cooperativa de Ibiaçá, a estratégia que mais aparece é "conversas do presidente e funcionários com os cooperados". Na cooperativa de Crissiumal a resposta com maior frequência é o desconto nas compras e negociações e também nos pagamentos.

Outra estratégia percebida em ambas as cooperativas é a assistência técnica e capacitações para aperfeiçoamento da produção leiteira. Na cooperativa de Ibiaçá o que os cooperados julgam como auxílio técnico é na verdade o auxílio que muitos cooperados tiveram para aquisição de tanques de expansão para o armazenamento do leite. Segundo estes produtores esta estratégia contribui para a visão de longo prazo porque a partir desta aquisição os cooperados se comprometem a permanecer na atividade por algum período e também se sentem mais pressionados a não deixarem a cooperativa por outras empresas. Nesta cooperativa também existe o papel do funcionário que realiza a inseminação artificial dos animais e transmite conhecimento técnico para fortalecer a produção leiteira.

Já na cooperativa de Crissiumal a assistência técnica que os cooperados consideram é um profissional que realiza a entrega das compras agropecuárias na propriedade. Entretanto, este profissional não possui nenhum tipo de formação na área. Ainda nesta cooperativa encontram-se cooperados que consideram não haver estratégias para minimizar o problema no momento. Já na cooperativa de Ibiaçá encontram-se cooperados que julgam a confiabilidade dos gestores como uma forte estratégia para minimizar o problema do horizonte, pois, consideram que a confiança repassada pelos gestores é essencial para manter os cooperados na organização.

O que se percebe é que algumas estratégias encontradas por Pivoto (2013) estão presentes nas organizações, porém, não são percebidas pelos cooperados como estratégias. Uma vez que, em ambas as cooperativas ocorrem a distribuição das sobras durante as assembleias gerais e também na cooperativa de Crissiumal existe a estratégia do programa com o quadro social através dos programas semanais de rádio. Assim, fica claro que as estratégias levantadas por autores como Cook (1995), Zilbersztajn (2002), Chaddad (2007) não estão presentes nestas organizações a partir da percepção dos cooperados.

Na sequência apresentam-se os resultados referentes ao problema do carona. Em trabalho realizado por Pivoto (2013) o problema do carona foi o segundo com maior média geral encontrado em seus resultados. Entretanto, no caso das cooperativas que atuam na área de produção do leite os resultados obtidos na pesquisa tiveram baixa concordância para este problema. De acordo com o autor isto ocorre porque estas organizações possuem um relacionamento mais estreito com os produtores, através da assistência técnica e a frequência das transações.

Dá-se início a esta discussão abordando a visão dos entrevistados sobre a existência de cooperados que apenas utilizam os benefícios da cooperativa, porém, não comercializam e investem na mesma. Tem-se que em ambas as cooperativas os respondentes consideram haver cooperados com este perfil. Entretanto, ressalta-se que em nenhuma das cooperativas existe uma resposta com mais evidência. Vale ressaltar que para alguns respondentes a existência de cooperados com este perfil já foi mais comum no início da formação da cooperativa.

Em se tratando do desvio da produção leiteira por parte dos cooperados para empresas que pagam mais pelo produto, tem-se que a maior parte dos respondentes afirma que é frequente ocorrer o desvio da produção. Vale ressaltar que todos funcionários ao serem questionados sobre essa pergunta, também responderam que é frequente o desvio da produção. Desta forma, percebe-se que há concordância entre a forma como os cooperados e os funcionários percebem esta questão na organização.

No que se refere à entrada de novos cooperados na organização e a possibilidade deste fato causar desincentivo para participar na cooperativa observou-se que, em ambas as cooperativas estudadas todos os respondentes afirmam que este fato não gera desincentivo.

Neste sentido, questionou-se os respondentes se eles julgam que deve haver benefícios distintos para estes dois grupos de cooperados. Nas duas cooperativas todos responderam que não 
deve haver nenhum tipo de diferenciação entre os cooperados e todos devem ser tratados da mesma maneira.

Da mesma forma, os respondentes afirmaram que não conhecem nenhum cooperado que tenha deixado a cooperativa alegando que os benefícios gerados também são apropriados por cooperados que não investem e participam da organização. Estes resultados se aproximam com os de Pivoto (2013), pois o autor encontrou que apenas uma cooperativa dentre as 16 analisadas apresentam alto valor de concordância para esta questão. Nas demais organizações estas variáveis não são expressivas, demonstrando que a entrada de novos cooperados na organização não é um fator de desincentivo à participação do conjunto de cooperados.

Desta forma, questionou-se aos entrevistados qual o motivo que leva os cooperados à deixarem a organização. Mais uma vez fica evidente que o principal motivo é o preço maior oferecido por outras empresas pelo produto. Quase a unanimidade dos entrevistados julgam este como o principal motivo.

Com base nestes resultados é possível trazer à discussão a concepção de Maraschin (2004) sobre o problema do carona. Para a autora o cooperado usa a estrutura da cooperativa quando esta oferece vantagens e negocia com outras organizações quando é conveniente. Neste caso, o que torna a saída dos produtores conveniente é o preço maior oferecido pela concorrência, mesmo que, na maioria das vezes esta diferença seja de poucos centavos. É isto que afirma o entrevistado da cooperativa de Ibiaçá: "o motivo é o preço maior que as empresas oferecem pelo litro de leite. Existe muita pressão das empresas por alguns centavos a mais".

Além deste cooperado, destaca-se o depoimento do entrevistado onde afirma que: para os produtores com produção mensal superior estes são mais pressionados pelas empresas e mais susceptíveis a deixarem a cooperativa já que, para estes produtores "alguns centavos por litro a mais" podem representar um ganho significativo.

Além deste motivo principal, destaca-se a opinião de um dos entrevistados da Cooperativa Ibiaçá. Para ele um motivo que condiciona a saída dos produtores da cooperativa é a exigência pela qualidade do leite. Na visão do mesmo, a cobrança constante pela qualidade do produto desestimula àqueles cooperados

que possuem algumas deficiências na qualidade do leite e não estão dispostos a melhorar para manter-se dentro dos padrões exigidos pela cooperativa. Assim, os mesmos deixam a organização e buscam empresas que ainda captam o leite sem observar padrões de qualidade em consonância com as leis em regimento.

Ao se referir sobre o tratamento que deve ser dado aos cooperados infiéis à cooperativa, encontra-se uma diferença entre as duas organizações analisadas. Na cooperativa de Crissiumal grande parte dos respondentes afirma que os cooperados infiéis devem ser excluídos do quadro social. Dentre os motivos que justificam esta opinião, destaca-se o depoimento do entrevistado da cooperativa Ibiaçá: "para mim eles devem ser excluídos do quadro social. Já que, ele deixou a cooperativa na mão, não cumpriu com seu dever de cooperado". Desta forma, a exclusão serviria como um alerta para os demais cooperados.

Já na cooperativa de Crissiumal a maioria dos respondentes mencionou que os cooperados infiéis não devem ser excluídos do quadro social. Para estes respondentes o motivo para a não exclusão é unânime. Segundo os entrevistados estes cooperados não deveriam ser desligados pois, em algum momento estes poderão retornar para a organização e isto pode ser benéfico para a cooperativa. Fica evidente que em ambas as cooperativas existem descontentamento em relação aos cooperados infiéis ou oportunistas, no entanto, a maioria advoga por penalidades brandas. Ou seja, existe certa proteção dos cooperados infiéis. Uma possível explicação para essa posição é a infidelidade eventual de todos os associados e, portanto, o medo de também ser punido caso seja adotado um mecanismo de diferenciação.

No que tange a percepção dos respondentes sobre a maneira como a infidelidade dos cooperados prejudica a cooperativa, tem-se que em ambas as organizações a resposta que aparece com maior frequência é a de que a infidelidade afeta as cooperativas negativamente, pois, com a saída dos cooperados a organização diminui o volume de leite arrecadado e desta maneira a mesma enfrenta dificuldade para negociar melhores preços com as empresas que adquirem o produto para o 
beneficiamento. Na cooperativa de Ibiaçá além desta questão, também surge o fato de que a infidelidade dos cooperados poderia eventualmente estimular a saída de outros associados da organização.

Já na cooperativa de Crissiumal surgem outras opiniões a respeito desta questão. Alguns cooperados não possuem a percepção de que a infidelidade dos associados poderia prejudicar a organização cooperativa. Entretanto, para outros a infidelidade é ruim, pois, diminui as transações dos cooperados infiéis com a cooperativa. Já para um dos entrevistados a infidelidade afeta os próprios cooperados, uma vez, que ao deixar a organização os mesmos podem passar a realizar negócios com empresas que não farão o pagamento pelo produto. Ressalta-se que o presidente desta organização já havia mencionado que alguns cooperados foram lesados por empresas ao deixarem a cooperativa, entretanto, isto não parece servir como estímulo para a permanência e fidelidade dos cooperados na organização.

Percebe-se que em ambas cooperativas analisadas a maior parte dos respondentes julga que o problema do carona é o principal entrave atualmente enfrentado pela organização. Contudo, destacam outros problemas que consideram relevantes. Assim, alguns respondentes destacam que a competição com grandes empresas é um grande problema, já que, as cooperativas não possuem condições de competir com as vantagens financeiras oferecidas por estas empresas, seja no preço do litro de leite ou em preços menores nas compras.

Além disso, destacam que as empresas possuem equipes de assistência técnica mais capacitada e atuante na propriedade, ao contrário das cooperativas que não apresentam quadros técnicos disponíveis para atender os cooperados. Na cooperativa de Crissiumal alguns cooperados afirmam não existir problemas na organização. Na sequência são apresentadas as considerações finais do artigo.

\section{Considerações finais}

Com base nos resultados anteriormente apresentados evidenciou-se que os problemas do carona e do horizonte estão presentes nas cooperativas de produtores de leite estudadas, apesar das características diferenciadas que as mesmas apresentam em relação às organizações com cunho empresarial.

Foi possível verificar que os produtores possuem uma visão de curto prazo quanto ao empreendimento cooperativo não estando dispostos a assumir riscos na organização, considerandose que os investimentos de curto prazo são mais seguros e com retorno mais rápido. Estes produtores também demonstraram estar mais preocupados com sua propriedade agrícola do que com a organização cooperativa não percebendo esta como uma organização que pode trazer benefícios econômicos. Ainda neste sentido, ficou claro que os cooperados preferem os benefícios econômicos imediatos através do preço do produto, por exemplo, não considerando as sobras operacionais como relevantes, apesar de esta última ser considerada por alguns cooperados como um diferencial destas organizações.

Além disso, foi possível identificar que os cooperados não possuem visão clara de seu papel dentro da organização, portanto, pois não cobram melhores resultados econômicos. Esta indefinição do seu papel dentro da organização gera espaço para ações oportunistas e estas ações acabam prejudicando a gestão e capitalização das organizações.

Ressalta-se a existência de outros problemas que não estes propostos para análise neste estudo. Tratam-se principalmente dos problemas relativos a saída dos produtores rurais da atividade leiteira e a não sucessão rural, sendo estes os grandes entraves que os gestores consideram que terão que enfrentar para manter as organizações nos próximos anos.

Pode-se considerar que os problemas oriundos dos direitos de propriedade difusos interferem e podem gerar ineficiências na gestão das organizações cooperativas de produtores de leite familiares no estado do Rio Grande do Sul. Portanto, para a sobrevivência destas organizações julga-se necessário que estratégias sejam adotadas e repensadas para minimizar os problemas de governança analisados e também aqueles problemas levantados pelas próprias organizações. Além do que, estas cooperativas devem buscar mecanismos a fim de mostrar aos cooperados o seu duplo papel de dono 
e usuário do empreendimento. Para que isto ocorra é necessário que os cooperados visualizem algum retorno ao participar destas organizações.

\section{Referências}

ANTONIALLI, L. M. Modelo de gestão e estratégias: o caso de duas cooperativas de leite e café de Minas Gerais. 2000. 238 f. Tese (Doutorado em Administração) - Faculdade de Economia, Administração e Contabilidade, Universidade de São Paulo, São Paulo, 2000.

BARTON, D. G. What is a cooperative? In: COBIA, D. (Ed.). Cooperatives in agriculture. New Jersey: Regents/Prentice Hall, 1989. Cap.1, p.1-20.

BENECKE, D. W. Cooperação e desenvolvimento: o papel das cooperativas no processo de desenvolvimento econômico nos países do Terceiro Mundo. Porto Alegre: Coojornal, 1980. (Coleção Cooperativismo, Debate 2).

BIALOSKORSKI NETO, S. Governança e perspectivas do cooperativismo. In: WORKSHOP INTERNACIONAL DE TENDÊNCIAS DO COOPERATIVISMO, 1998, Ribeirão Preto. Anais... Ribeirão Preto: PENSA/FUNDACE/FEARP-USP, 1998.

BIALOSKORSKI NETO, S. Agronegócio Cooperativo. In BATALHA, M. (Org). Gestão Agroindustrial. São Paulo: Atlas, 2001.

BIALOSKORSKI NETO, S. Gobierno y papel de los cuadros directivos en las cooperativas brasileñas: estudio comparativo. Revista de Economía Pública Social y Cooperativa, Valencia, n. 48, abr. 2004 .

BIALOSKORSKI NETO, S. Governança e perspectivas do cooperativismo. In: WORKSHOP INTERNACIONAL DE TENDÊNCIAS DO COOPERATIVISMO, 1998, Ribeirão Preto. Anais... Ribeirão Preto: PENSA/FUNDACE/FEARP-USP, 1998.

BIALOSKORSKI NETO, S. Gestão do Agribusiness Cooperativo. In: BATALHA, M.O. (org.). Gestão Agroindustrial. São Paulo: Atlas, 1997. v. 1

BIALOSKORSKI NETO, S.; CHADDAD, F.R. Estrutura de propriedade e finanças em cooperativas agropecuárias: um ensaio comparativo sobre a influência do ambiente institucional no Brasil e nos Estados Unidos. In: CONGRESSO DA SOCIEDADE BRASILEIRA DE ECONOMIA E SOCIOLOGIA RURAL, 43., 2005, Ribeirão Preto. Anais... Ribeirão Preto, SP: SOBER/USP/FEA, 2005 .

BITENCOURT, M.; AMODEO, N. B. P; VALADARES, J. H. Cooperativismo nos garimpos: potencialidades e limitações a partir de um estudo de caso. Organizações Rurais \& Agroindustriais, Lavras, v. 12, n. 3, p. 399-410, 2010.

BOESCHE, L.; MAFIOLETTI, R. L. Evolução e indicadores do cooperativismo brasileiro e paranaense. Curitiba: SISTEMA OCEPAR, 2005.

CHADDAD, F.R. Cooperativas no agronegócio do leite: mudanças organizacionais e estratégicas em resposta à globalização. Organizações Rurais e Agroindustriais, Lavras, v. 9, n. 1, p. 69-78, 2007.

CHRISTOPLOS, I. Mobilizing the potential of rural and agricultural extension. Roma: FAO, 2010. 
COASE, R. H. The firm, the market and the law. Chicago: The University of Chicago Press, 1988. $217 \mathrm{p}$.

COOK, M. L. The future of US agricultural cooperatives: a neo-institucional approach. American Journal of Agricultural Economics, Oxford, v. 77, p. 1153-1159, dec. 1995.

COSTA, D. R. M. Propriedade e decisões de gestão em organizações cooperativas agropecuárias brasileiras. 2010. Tese (Doutorado em Economia Rural) - Fundação Getúlio Vargas, São Paulo, 2010.

FAMA, E.; JENSEN, M. Separation of ownership and control. Journal of Law and Economics, Chicago, v. 26, n. 2, p. 301-327, 1983.

FEIJÓ, R. L. C. Economia agrícola e desenvolvimento rural. Grupo Gen-LTC, 2010.

GROSSMAN, S. J.; HART, O. D. The costs and benefits of ownership: a theory of vertical and lateral integration. Journal of Political Economy, Chicago, v. 94, n. 41, p. 691-719, 1986.

FERREIRA, G. M. V. Governança e sua relação com a fidelidade em cooperativas. 2014. Tese (Doutorado em Extensão Rural) - Universidade Federal de Santa Maria, Santa Maria, 2014.

HART, O. Firms, Contracts, and Financial Structure. Oxford: Oxford University Press, 1995.

JENSEN, M. C.; MECKLING, W.H. Theory of the firm: managerial behaviour, agency costs and ownership structure. Journal of Financial Economics, Oxford, v. 3, p. 305-36o, 1976.

LANGLOIS, R.N.; FOSS, N.J. Capabilities and Governance: the Rebirth of Production in the Theory of Economic Organization. [S.1.]: Danish Research Unit for Industrial Dynamics, Jan. 1997.

LIMA, Romeu Eugênio de; ARAÚJO, Marcelo Bicalho Viturino de; AMARAL, Hudson Fernandes. Conflitos de agência: um estudo comparativo dos aspectos inerentes a empresas tradicionais e cooperativas de crédito. Revista Contabilidade e Organizações, São Paulo, v.2, n.4, p. 148-157, set/dez 2008.

MARASCHIN, A. F. As relações entre produtores de leite e as cooperativas: um estudo de caso na bacia leiteira de Santa Rosa - RS. 2004. 145 f. Dissertação (Mestrado) - Programa de PósGraduação em Desenvolvimento Rural, Faculdade de Ciências Econômicas, Universidade Federal do Rio Grande do Sul, Porto Alegre, 2004.

MILGROM, P.; ROBERTS, J. Economics, organization \& management. New Jersey: Prentice Hall, 1992.

PINHO, D.B. O Pensamento Cooperativo e o Cooperativismo Brasileiro. São Paulo: CNPq, 1982. V. 1

PIVOTO, D. Os problemas dos direitos de propriedades difusos em cooperativas agropecuárias. 2013. Dissertação (Mestrado em Agronegócios) - Programa de Pós-Graduação em Agronegócios, Centro de Estudos e Pesquisas em Agronegócios, Universidade Federal do Rio Grande do Sul, Porto Alegre, 2013.

SEGATTO-MENDES, A. P. Teoria de agência aplicada à análise de relações entre os participantes dos processos de cooperação tecnológica universidade-empresa. (Tese de doutorado). Faculdade de Economia, Administração e Contabilidade. USP. São Paulo. 2001. 
SERIGATI, F.C. Fidelidade e Governança Corporativa em Cooperativas: um estudo empírico com as cooperativas paulistas. 2008. Dissertação (Mestrado em Economia) - Fundação Getúlio Vargas, São Paulo, 2008.

SYKUTA, M.E.; COOK, M.L. A new institutional economics approach to contracts and cooperatives. American Journal of Agricultural Economics, Columbia, v. 83, n. 5, sep. 2001.

VALADARES, J. H. Estrutura e estratégia institucional:formação de campo organizacional e isomorfismo no cooperativismo de crédito rural de Minas Gerais. 2003. $126 \mathrm{f}$. Tese (Doutorado em Desenvolvimento, Agricultura e sociedade) - Universidade Federal Rural do Rio de Janeiro, Seropédica, 2003.

WILLIAMSON, O. The economic institutions of capitalism: firms, markets, relational contracting. New York: The Free Press, 1985.

ZYLBERSZTAJN, D. Quatro estratégias fundamentais para cooperativas agrícolas. In: BRAGA, M.J.; REIS, B.S. (Org.) Agronegócio cooperativo: reestruturação e estratégias. Viçosa: Suprema, 2002. p. 55-76. 